\title{
HENGEVELD, KEES Y J. LACHLAN MACKENZIE (2008): FUNCTIONAL DISCOURSE GRAMMAR. A TYPOLOGICALLY-BASED THEORY OF LANGUAGE STRUCTURE. OXFORD, OXFORD UNIVERSITY PRESS. XXIV + 503 PÁGS.
}

\author{
Ventura Salazar García \\ Universidad de Jaén \\ vsalazar@ujaen.es
}

Dentro del complejo y heterogéneo panorama de la teoría gramatical contemporánea, el llamado funcionalismo holandés constituye sin duda uno de los movimientos más sólidos y productivos. Durante las últimas décadas del siglo XX, dicho movimiento se articulaba primordialmente en torno al modelo conocido como Gramática Funcional, diseñado por Simon C. Dik (1940-1995). La prematura muerte de este autor -así como, poco tiempo después, la de A. Machtelt Bolkestein, una de sus más estrechas colaboradoras- supuso un duro golpe que generó una lógica incertidumbre sobre el porvenir de dicho modelo. No obstante, los años posteriores no sólo han disipado tales dudas, sino que han puesto de relieve cómo este enfoque teórico, lejos de quedarse estancado en el valioso legado de Dik, ha sabido evolucionar y enfrentarse a nuevos retos de una forma a la vez coherente y sugestiva. El libro al que se dedica la presente reseña es buena prueba de ello. Se trata de una monografía que tiene como objetivo ofrecer una exposición pormenorizada de un nuevo modelo, bautizado como Gramática Funcional del Discurso (en inglés: Functional Discourse Grammar), el cual, sin dejar de ser heredero directo del funcionalismo holandés precedente, se aparta de él en no pocos aspectos teóricos de primer orden. Como señalan los propios autores al comienzo del prefacio (pág. xi), el primer esbozo de la Gramática Funcional del Discurso -por entonces aún concebida como una reorganización interna, o nueva arquitectura, del modelo dikeano- tuvo lugar en España, en el seno del $9^{\circ}$ Congreso Internacional de Gramática Funcional, organizado por la UNED y celebrado en Madrid en septiembre de 2000. Otras publicaciones posteriores han ido ampliando y concretando su diseño, pero cabe afirmar que la aparición de este libro supone un punto de inflexión, al dotarla por primera vez de lo que podemos calificar como una versión estándar.

La obra de Hengeveld y Mackenzie consta de un total de cinco capítulos, precedidos de un prefacio, un listado de tablas y figuras y otro más de abreviaturas y símbolos. Cierran el libro el apartado de referencias bibliográficas y los índices de rigor. El prefacio, relativamente breve, explica sucintamente el origen y gestación de este nuevo modelo, así como los puntos principales de convergencia y divergencia con la Gramática Funcional de Dik. Como es habitual, se incluye aquí también la nómina de agradecimientos. Pasaré ahora a exponer el contenido de cada uno de los capítulos. Debo advertir que la traducción al español de los tecnicismos usados en el libro procederá en muchos casos de mi propia cosecha. Cuando 
estime que alguno de ellos podría ser problemático, añadiré el término original inglés en cursiva y entre paréntesis.

El primer capítulo, de carácter introductorio, resulta de crucial importancia porque fija los principios básicos de partida, sintetiza los aspectos fundamentales del modelo y, en definitiva, aporta las claves interpretativas necesarias para una adecuada comprensión del resto del libro, especialmente por lo que se refiere a sus convenciones de formalización. Ya en vida de Dik, varios seguidores de la Gramática Funcional plantearon que dicho modelo debía dejar de ser una teoría oracional para tomar en consideración los hechos discursivos de las lenguas. El debate que se suscitó por entonces es si esa ampliación debía tener lugar mediante la introducción de un nuevo módulo en la gramática (relativamente autónomo respecto del resto de componentes de la teoría), o bien mediante la adición de un nuevo nivel sintagmático, integrado dentro de la representación jerarquizada de la estructura de las expresiones lingüísticas. La Gramática Funcional del Discurso nació a raíz de ese debate, al que aporta una solución que a la vez aúna y supera esa dicotomía. Su punto de arranque es una teoría de la interacción verbal que consta de cuatro componentes: el conceptual, el contextual, el gramatical y el de emisión (output component). El objeto de estudio de la gramática es, obviamente, el componente gramatical, en el que tienen lugar la formulación y la codificación de las expresiones lingüísticas. Tales operaciones van asociadas a diferentes niveles de representación. Así, atañen a la formulación el nivel interpersonal -que esencialmente es de naturaleza pragmático-discursiva- y el nivel representacional, prioritariamente semántico. La codificación, por su parte, es por una parte morfosintáctica, y por otra fonológica, con sendos niveles de representación en cada caso. Esto supone un total de cuatro niveles gramaticales. En todos estos niveles se cuenta con la existencia de un conjunto de entidades primitivas, pero, en última instancia, las reglas que determinan su funcionamiento son específicas para cada lengua. Esto es importante sobre todo por lo que se refiere a la formulación, ya que, a diferencia de otras teorías gramaticales contemporáneas, la Gramática Funcional del Discurso no asume la existencia de nociones semánticas o pragmáticas universales (cf. pág. 12). Cada nivel de representación se organiza por sí mismo, sin depender de los demás. Ahora bien, todos ellos coinciden en disponer las unidades lingüísticas que les son propias dentro de una estructura sintagmática jerarquizada en la que intervienen diversos planos (layers). De ese modo, tal como he señalado anteriormente, el modelo consigue integrar un funcionamiento modular, por niveles, con una estructuración jerarquizada, por planos.

Antes de concluir las referencias al capítulo introductorio, conviene resaltar al menos dos aspectos importantes. En primer lugar, que nos hallamos ante un modelo que cuenta con una organización descendente (top-down organization), en el sentido de que parte de la intención comunicativa del hablante, y no de unidades lingüísticas discretas (como pueden ser, por ejemplo, las unidades léxicas contenidas en un lexicón). Esto viene motivado por la voluntad de dotar a la teoría de un mayor grado de adecuación psicológica, y supone una notable diferencia no sólo respecto de la Gramática Funcional, sino también de otros muchos modelos precedentes, como el lexicalismo chomskyano, las gramáticas de unificación y rasgos, etc. En segundo lugar, merece a mi juicio una valoración muy positiva el hecho de que la codificación gramatical, ya sea morfosintáctica o fonológica, queda plenamente deslindada de la materialización física, que tiene lugar en el componente de salida. De ese modo, la estructura gramatical mantiene lo que Hengeveld y Mackenzie denominan una naturaleza digital, independientemente de que su manifestación tenga lugar en forma oral, escrita, como monólogo 
interior, etc. Asimismo, esta distinción posibilita que la Gramática Funcional del Discurso sea plenamente operativa para el análisis de las lenguas de signos de las comunidades sordas, cuya transmisión primaria tiene lugar por vía visogestual.

Tras el capítulo introductorio, los cuatro restantes están dedicados a cada uno de los niveles de representación que han sido formulados para el componente gramatical. Se inicia el recorrido con el nivel interpersonal, que atiende los aspectos gramaticalmente relevantes para el uso de las unidades lingüísticas en la interacción verbal. Por tanto, se desenvuelve en un ámbito esencialmente pragmático-discursivo. Este nivel cuenta con las siguientes capas: la más general es el turno o intervención (Move). Lo importante del turno es que constituye un evento comunicativo unitario, por más que su materialización admita múltiples posibilidades (desde un simple grito a un tratado en varios volúmenes). El turno está formado por uno o varios actos discursivos en los que participan un hablante, uno o más oyentes, una fuerza ilocutiva y un contenido comunicado. Este último, a su vez, puede estar formado por uno o más subactos, que se clasifican básicamente en dos tipos: subactos de referencia-identificar por medios lingüísticos una determinada entidad, o conjunto de entidades, dentro de un mundo real o posible- y subactos de adscripción, por los cuales se asigna -a una o más entidadesdeterminada propiedad o relación. En cada uno de los planos de esta estructura jerarquizada, salvo en la última, se contemplan diversas unidades primitivas que funcionan como núcleos (heads), modificadores u operadores, que interactúan sintagmáticamente dentro de diversos marcos (frames).

El tercer capítulo está dedicado al nivel representacional, de naturaleza eminentemente semántica. En buena medida, se corresponde con los medios lingüísticos que permiten desempeñar lo que Halliday denominó en su día función ideacional. Mientras otras corrientes contemporáneas -verbigracia, la lingüística cognitiva- postulan que entre semántica y pragmática existe un continuum sin fronteras discretas, la Gramática Funcional del Discurso fija por el contrario una separación estricta entre ambas (cf. págs. 128-130; particularmente la delimitación entre el concepto interpersonal de referencia y el representacional de denotación), lo cual queda materializado en dos niveles autónomos. La organización del nivel representacional se lleva a cabo a partir de una serie de categorías semánticas, que constituyen los distintos planos estructurales con sus propios núcleos, modificadores y operadores. Las cuatro categorías básicas son en buena medida deudoras de la tipología de entidades de Lyons: ente (individual), propiedad (no contemplada inicialmente por Lyons), estado de cosas (state of affairs) y contenido proposicional. Otras categorías adicionales, relevantes en términos gramaticales, son las de ubicación, tiempo, episodio, manera, razón y cantidad. Asimismo, cada categoría puede dividirse a su vez en diversas subcategorías. Por ejemplo, un ente puede clasificarse en contable ('libro'), no contable ('agua') y colectivo ('rebaño'); los estados de cosas pueden ser dinámicos o estáticos; etc. Ahora bien, la relevancia gramatical de tales categorías y subcategorías fluctúa de una lengua a otra, en virtud de reglas idiomáticas específicas.

Con el nivel representacional se completa la formulación de las expresiones lingüísticas. El paso siguiente es su codificación, que tiene lugar en dos niveles: morfosintáctico y fonológico. El nivel morfosintáctico, objeto del capítulo cuarto, dota de una organización unitaria al material lingüístico aportado por los niveles interpersonal y representacional, optimizando su interpretabilidad. La jerarquización de la estructura morfosintáctica tiene como unidad básica en su plano superior la expresión lingüística en su conjunto, la cual está formada 
prototípicamente por una o más cláusulas. Las capas morfosintácticas inferiores están representadas por el sintagma (phrase) y la palabra. Este nivel morfosintáctico cuenta también con otras unidades primitivas, como son los esquemas morfosintácticos (Morphosyntactic Templates), los morfemas -libres o ligados-y los operadores morfosintácticos.

El capítulo final está dedicado al nivel fonológico, que completa la codificación y, por ende, la plena especificación subyacente de la expresión lingüística. Se convierte así en el material de entrada (input) con el que operará el componente de emisión. Siguiendo, con ligeras adaptaciones, la teoría de Nespor y Vogel, se defiende aquí la existencia de una estructura fonológica jerarquizada, con seis planos: enunciado, frase entonativa, frase fonológica, palabra fonológica, pie y sílaba. Paralelamente a lo que ocurre con el morfema en el nivel morfosintáctico, aquí el fonema no genera un plano específico, aunque obviamente es la unidad segmental básica para la construcción de sílabas. Cada uno de los planos mencionados se asocia a fenómenos fonológicos que les son propios y que en buena medida determinan la variación tipológica en este nivel de análisis (con distinciones tales como la de lenguas basadas en la sílaba y lenguas basadas en la palabra). Las unidades fonológicas primitivas son esencialmente los patrones prosódicos, las secuencias segmentales y los operadores.

Creo que lo expuesto hasta aquí da cuenta, siquiera sea de modo aproximado, de la excepcional envergadura del libro de Hengeveld y Mackenzie, el cual está llamado a ser sin duda una referencia obligada en la teoría gramatical de los próximos años. Indiscutiblemente, la Gramática Funcional del Discurso se revela aquí como uno de los modelos teóricos más ambiciosos, atractivos y abarcadores de nuestros días. Incluso quienes no compartan sus postulados deben admitir el amplio bagaje empírico con el que son defendidos. Merece subrayarse al respecto el apoyo proporcionado por un abundante material de naturaleza tipológica. Ése fue ya uno de los puntos fuertes de la Gramática Funcional de Dik, desde sus orígenes, y su importancia en la obra que ahora nos ocupa queda incluso reflejada en su subtítulo. Baste señalar que hay referencias a más de ciento sesenta lenguas. También resulta a mi juicio sumamente relevante el hecho de incorporar un nivel fonológico ampliamente desarrollado, lo cual es poco habitual en otros modelos gramaticales, donde la fonología rara vez pasa de ser algo más que un apéndice o un desideratum.

En otro orden de cosas, hay que resaltar cómo la continuidad con el pensamiento dikeano, dentro de un mismo paradigma científico, no es óbice para reconocer las enormes diferencias -no sólo de organización y procedimiento, sino también conceptuales- existentes entre ambos enfoques. Como muestra, puede constatarse que mientras las funciones semánticas, sintácticas y pragmáticas eran para Dik los verdaderos ejes vertebradores de toda la gramática, para Hengeveld y Mackenzie desempeñan un papel sensiblemente más limitado, que se relaciona sobre todo con el alineamiento sintagmático (alignment) de los constituyentes, en su tránsito desde los niveles pragmático y semántico al morfosintáctico (cf. págs. 316-332). Por último, advertiré que el modelo ahora presentado, pese a su clara voluntad de trascender el ámbito oracional para adentrarse en los fenómenos discursivos, no guarda realmente una conexión directa con las corrientes pragmáticas y textuales de mayor difusión. De entre todas ellas, únicamente la teoría de los actos de habla tiene una presencia tangible en el nivel interpersonal. En cambio, debo reconocer que para mí fue una sorpresa constatar que conceptos tales como implicatura, cohesión, relevancia, etc. ni siguiera aparecen recogidos en el índice temático. Personalmente, estimo que éste es un aspecto en el que los partidarios de la Gramática Funcional del Discurso deberían indagar más, con vistas a establecer unos 
más sólidos puentes de contacto entre su teoría gramatical y otros acercamientos a la realidad pragmático-discursiva de las lenguas. Se trata de una cuestión que no merma ni un ápice la excepcional calidad del trabajo ofrecido por Hengeveld y Mackenzie, pero sí puede servir de pequeño botón de muestra de las enormes dificultades que entraña el objetivo último que se han fijado ambos autores, el cual probablemente está aún lejos de haber sido alcanzado. Por tanto, hay que entender este libro, no como un punto de llegada, sino como un punto de partida gracias al cual se abren perspectivas sumamente prometedoras para futuras investigaciones gramaticales de amplio alcance. 